\title{
Sensory Neuron
}

National Cancer Institute

\section{Source}

National Cancer Institute. Sensory Neuron. NCI Thesaurus. Code C12628.

An afferent neuron that converts environmental stimuli into electrical impulses that are transmitted to the central nervous system. 